\title{
An obstructive, proximally migrated plastic biliary stent extracted with a "modified" Seldinger technique and a polypectomy snare
}

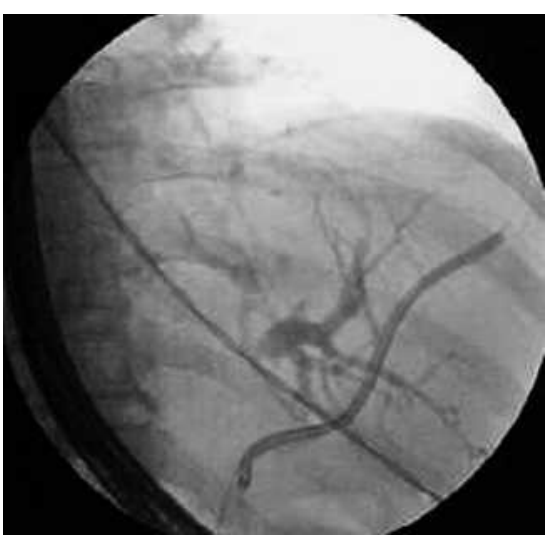

Fig. 1 Guide wire inside the stent from the flap-hole.

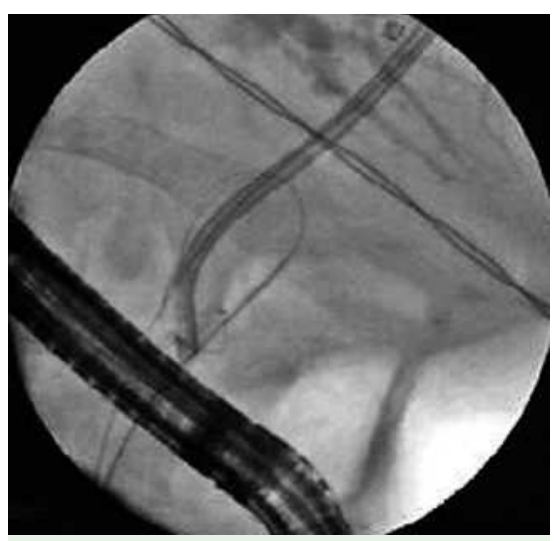

Fig. 2 Snare catching the biliary stent.

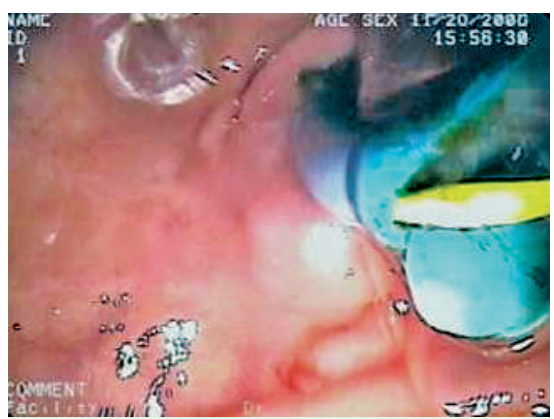

Fig. 3 Endoscopic view of the plastic stent, with the wire inside the flap-hole, and caught with the snare.
Endoscopic retrieval of proximally migrated, plastic biliary stents may be technically challenging and sometimes unsuccessful [1]. Data from the literature report a retrieval success rate of $85 \%$, with the remaining $15 \%$ requiring surgical removal [2]. The choice of retrieval technique is dependent on several factors, including biliary ductal dilatation, depth of stent migration, distal stent impaction, and biliary stricture distal to the migrated stent. The placement of an additional stent alongside an irretrievable stent has been reported as an alternative technique to retrieval, but the risk of cholangitis associated with this technique is not yet widely known by practitioners [3]. Despite the widespread use of such stents, there are few reports on the technique and the different accessories available for retrieval of migrated stents. Furthermore, there are no reports in the literature on proximally migrated, biliary stent removal using a polypectomy snare.

A 53-year-old man with a history of chronic pancreatitis underwent endoscopic retrograde cholangiopancreatography (ERCP) with biliary stent insertion in September 2006, for distal common bile duct benign stenosis. On November 2006 he was referred to our center after developing cholangitis. An ERCP was carried out, and the abdominal pre-procedural radiograph showed a proximal migration of the biliary stent. Different techniques were utilized to retrieve the stent (Dormia basket, forceps, balloon, Sohendra extractor), but all of them failed. It was not possible to insert a guide wire into the distal orifice of the stent because the angulated distal part of the stent was too close to the biliary wall. With a sphincterotome, which allowed us to address the direction, a wire was inserted through the distal flap-hole, and into the stent ( $\bullet$ Fig. 1). Over the wire, a polypectomy snare was placed as far as the distal edge of the stent and then opened, thus catching the stent ( $\odot$ Fig. 2 ). The stent was then successfully removed ( $\bullet$ Fig. $\mathbf{3}$ ).

\section{B. Mangiavillano, E. Masci}

Department of Gastroenterology and Gastrointestinal Endoscopy, IRCCS Vita-Salute San Raffaele University, San Raffaele Hospital Scientific Institute, Milan, Italy

\section{References}

1 Tarnaski PR, Cotton PB, Baillie J et al. Proximal migration of biliary stents: attempted endoscopic retrieval in forty-one patients. Gastrointest Endosc 1995; 42: 513 - 520

2 Lahoti S, Ctalano MF, Geenen JE, Schmalz MJ. Endoscopic retrieval of proximally migrated biliary stents: experience of a large referral center. Gastrointest Endosc 1998; 47: 486 491

3 Chaurasia OP, Rauws EA, Fockens P, Huibregtse $K$. Endoscopic techniques for retrieval of proximally migrated biliary stents: the Amsterdam experience. Gastrointest Endosc 1999; 50: 780-785

Bibliography

DOI $10.1055 / \mathrm{s}-2007-966478$

Endoscopy 2007; 39: 256

(c) Georg Thieme Verlag KG Stuttgart · New York . ISSN 0013-726X

\section{Corresponding author}

\section{B. Mangiavillano, MD}

Vita-Salute San Raffaele University

IRCCS San Raffaele Hospital

Gastroenterology and

Gastrointestinal Endoscopy Unit

Via Olgettina 60

20132 Milan

Italy

Fax: +39-02-26432504

mangiavillano.benedetto@hsr.it 